DOI: $\underline{\text { https://doi.org/10.24867/11FA08Panic }}$

\title{
PRINCIPI EKOLOŠKE GRADNJE I ANALIZA EKO NASELJA BANŠTAD U HAJDELBERGU
}

\section{PRINCIPLES OF ECO BUILDING AND ANALYSIS OF ECO DISTRICT BAHNSTADT IN HEIDELBERG}

\section{Aleksandra Panić, Fakultet tehničkih nauka, Novi Sad}

\section{Oblast - ARHITEKTURA}

Kratak sadržaj - Tema ovog rada jeste analiza principa ekološke gradnje, različiti sertifikicaioni sistemi primenjeni na specifične sektore industrije $i$ proizvodnje $i$ uspešni primeri eko objekata $i$ distrikata iz celog sveta. Takođe, kao predmet razrade $i$ razmatranja glavnog tehničkog projekta uzeta je revitalizacija objekta nekadašnjeg depoa Železničke stanice, za koju je predviđen projekat obnove prema ekološkim principima, s obzirom, da se nalazi u većoj celini eko naselja Banštad u Hajdelbergu, te samim tim podleže specifičnim $i$ interesantnim zahtevima investitora.

Ključne reči: eko naselje, obnovljiva arhitektura, revitalizacija, obnova

\begin{abstract}
The topic of this project is the analysis of the principles of ecological construction, various certification systems applied to specific sectors of industry and production, and presenting successful examples of ecological facilities and districts fromall around the world. Also, the revitalization of the building of the former depot of the Railway Station was taken as a subject of analysis and further technical analysis and design, hence as it is part of broader eco district Bahnstadt in Heidelberg, it is subject to specific, strict eco and sustainable requirements.
\end{abstract}

Keywords: eco district, design, sustainable architecture, revitalisation, object renewal

\section{UVOD}

Sa obzirom na aktuelnost teme održivosti i ekološke gradnje, ovaj projekat daje uvid u moguće načine impliciranja koncepta održivosti u savremenu arhitekturu, osvetljavajući ukupne ciljeve, standarde održivosti, građevinske materijale i procese razvoja projekata sa naglašenim akcentom na održivosti. $U$ tom smislu, analizom projekta Banštad i pristupa energetskoj efikasnosti, kao jednog od najvažnijih ciljeva u postizanju održivosti u arhitekturi, ovaj master rad fokusiraće se na međunarodne, nacionalne i lokalne propise, nivoe sertifikata i ograničenja koja treba uzeti u obzir za izradu arhitektonskog projekta.

\section{NAPOMENA:}

Ovaj rad proistekao je iz master rada čiji mentor je bila dr Jelena Atanacković Jeličić, red. prof.
Takođe, kako bi se dokazala ostvarivost ovih ideja, ne samo u teoriji već i u praksi, priložen je i detaljan projekat revitalizacije depo Železničke stanice u Hajdelbergu, u okviru eko naselja Banštad.

\section{LOKACIJA}

Hajdelberg je univerzitetski grad u nemačkoj pokrajini Baden-Virtemberg, smešten na reci Nekar na jugozapadu Nemačke.

Jedan od najvažnijih aspekata ovog multikulturnog grada jeste plemenita akademska istorija - naime, u Hajdelbergu se nalazi najstariji nemački univerzitet, osnovan 1386. godine.

Koncept projekta Banštad je ideja o stvaranju okruga koji se može pohvaliti stambenom arhitekturom, istraživačkim objektima, komercijalnim i zabavnim aktivnostima i poslovima u skladu sa tradicijom Hajdelberga. To je istovremeno jedna od najvećih svetskih naselja pasivnih kuća i jedan od najvećih projekata urbanog razvoja u Nemačkoj.

\subsection{Analiza lokacije}

Lokacija trenutnog naselja Banštad (Bahnstadt) je nekadašnji skladišni prostor za teretne i ranžirne stanice na jugozapadu centra grada Hajdelberga, slika 1.

Područje takođe uključuje bivša vojna nalazišta koja su postala dostupna za ponovnu civilnu upotrebu. Ukupna površina iznosi 102,5 hektara, od čega su $61 \%$ površina zgrade, $18 \%$ zelene površine i otvoreni prostori i $21 \%$ saobraćajne mreže.

Depo tj skladište Železničke stanice (Bahnbetriebswerk), koje je predmet analiziranog projekta, je u sklopu postojeće, glavne Železničke stanice u gradu Hajdelbergu (nem. Heidelberg), u Nemačkoj. Deo je kompleksne i veoma razgranate infrastrukture železnica u regiji BadenVurtemberg (nem. Baden-Württemberg), koje se nalazi na jugozapadnom delu Nemačke.

Kako je železnički saobraćaj imao izuzetan značaj za privredni razvoj Nemačke i prevoz vojnih i trgovačkih sirovina tokom II Svetskog rata, ovaj sistem podrazumeva obimnu infrastrukturu železničkih objekata (glavnih i pomoćnih), u koje spadaju zgrade Železničkih stanica, rampi, tranzitnih stanica, skladišta i radionica za prepravke na vagonima i lokomotivama. 


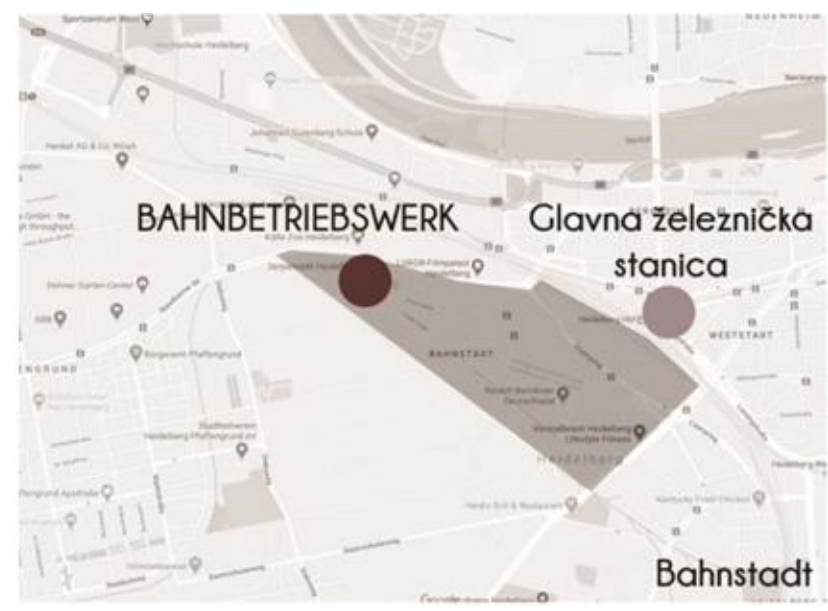

Slika 1. Pozicija naselja Banštad i analiziranog kompleksa

S obzirom da je skladište Železničke stanice deo širog kompleksa Banštada, koji je u državno-privatnom vlasništvu, on je delimično obnovljen u poslednjim decenijama i periodično održavan.

Izučavajući planove i projekte namenjene za ovaj deo grada, zaključuje se da je Bahnbertiebswerk segment detaljno razrađenog plana restauracije železničkog sistema, te se očekuje rekonstrukcja i prenamena objekta tokom sledećih decenija.

\section{KONCEPT}

U morfološkom smislu, koncept jeste da se postojeći izgled objekta menja u što manjoj meri (po principu Reuse/Reduce/Recycle), uz minimalna rušenja i finansijske troškove, kako bi se odala počast nekadašnjem značaju ovog objekta i kako bi se maksimalno ispoštovao karakterističan duh prostora tj genius loci.

To će biti ostvareno tako što je zapadna zona netaknuta $u$ morfološkom i fizičkom smislu (menja se samo namena objekata i unutrašnja organizacija u što manjoj meri), dok je u istočnoj nastavljen postojeći skeletni sistem betonskih stubova, koji stvara karakteristične kutkove i zanimljiv odnos definisanje prostora kroz periodično menjanje ambijenata puno-prazno.

Poštujući osnovnu tendenciju da se objekat, u fizičkom smislu menja u minimalnim okvirima, time poštujući nekadašnji značaj i kvalitet prvobitne konstrukcije i arhitekture objekta, najveći akcenat je stavljen na modifikaciju željenog sadržaja i namene objekta.

Odlučeno je da se napravi kombinacija namena, koje su logički povezane i koje se međusobno prožimaju sa obzirom da objekat po svojoj kompleksnosti i veličini, može da primi mnogostruke funkcije, slika 2. i slika 3 .

Fokus je stavljen na organsku formu, koja se nadovezuje na postojeću simetričnu ortogonalnu i kubusnu formu, sa unutrašnjim dvorištima koji varijaju po dimenzijama, tako stvarajuće intimne i javne prostore, čija se funkcija $u$ zavisnosti od potreba može menjati tokom vremena.

\subsection{Pozicioniranje objekta}

Velikim mogućnostima za oplemenjivanje i ponovno otkrivanje potencijala ovog objekta, doprinosi i činjenica da je Bahnbetriebswerk, ulazna kapija sa zapadne strane za jedan od najambicioznijih projekata u celoj NemačojBanštad.

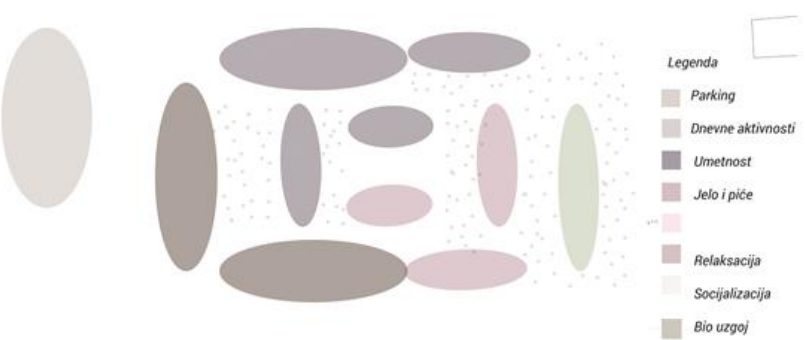

Slika 2. Šematski prikaz finalnog koncepta

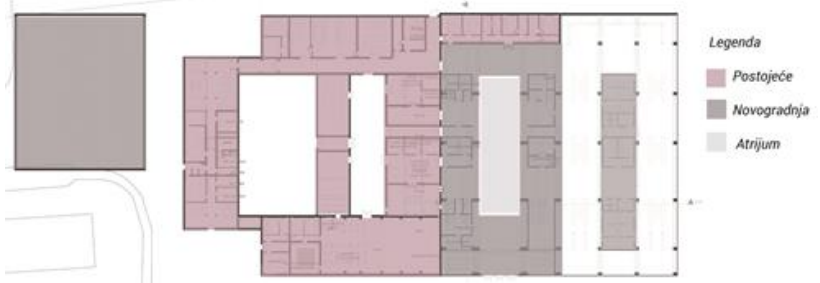

Slika 3. Šematski prikaz odnosa postojećeg $i$ novoizgrađenog

Ovo je kompleksni, urbanistički projekat izgradnje celokupnog novog naselja grada, koji se odlikuje izvanrednim ekološkim dostignućima- naime, Bahnstadt je sa svojom igradnjom postao nejveće ekološki pasivno naselje u celoj Evropi. Sa obzirom na kompleksnost projekta, zvaničan završetak radova je predviđen za 2022. godinu (radovi su otpočeti 2008. godine) i do sada su izgrađeni mnogobrojni objekti mešovite namene, poslovni, edukativni i stambeni objekti, za čiju izgradnju su korišćeni najmoderniji materijali i sistemi gradnje.

\section{TEHNIČKI OPIS OBJEKTA}

\subsection{Konstruktivni sistem}

Izraženi masivni sistem, sa zidovima od opeke debljine $40-50 \mathrm{~cm}$ i materijalizacija od tamno crvene opeke, predstavljaju glavnu tačku prepoznavanja javnih objekata u Nemačkoj, iz period a 50ih i 60ih godina XX veka.

$\mathrm{Na}$ južnoj fasadi je evidentna jasna podela u pravcu istokzapad, gde je zapadna strana celokupno od kamena, odrađena u stilski definisanom i karakterističnom stilu, dok je istočna zona mnogo više oštećena i predstavlja ogoljenu skeletnu konstrukciju betonskih stubova, sa jasnom raspodelom i stalnim rasponom od po $4 \mathrm{~m}$ između fasada.

Ovakav raster se proteže celom unutrašnjošću istočnog dela kompleksa, te je prisutan konstantan, uravnotežen sistem stubova i potpornih stubova, te se stiče utisak da je kompleks depoa podeljen na 2 dela- istočni i zapadni.

Obe strane su po originalnom projektu imale zajedničku krovnu konstrukciju, međutim sa vremenom, retkim ulaganjima u objekat, krovna konstrukcija je značajno urušena i u veoma lošem stanju, dok je u istočnom delu srušena i tokom poslednjih decenija XX veka skinuta, te je trenutno ova zona pod stalnim udarima vetra, kiše i ostalih vremenskih nepogoda.

\subsection{Materijalizacija}

Objekat je izgrađen od crvene opeke, karakteristične za period izgradnje, sa elementima od kamena (pretežno na 
obodima prozorskih venaca, ulaznih zona kao i sokla) i stakla.

Zapadna fasada se sa svojom detaljnošću izdvaja kao primarna fasada, koja je i kroz vreme najbolje očuvana.

Takođe, severna fasada se izdvaja po izraženo vertikalnoj simetriji, i nizu prozorskih otvora, multipliciranih celom dužinom fasade, koji daju ritmičnost i sklad fasadi koja je direktno okrenuta ka železničkoj pruzi, te je namenski izvedena sa posebnom pažnjom i detaljnošću.

Južna fasada je usled požara, tokom XX veka, delimično oštećena i nije u najboljem stanju, te je čak i osnovna konstrukcija delom narušena, kao i opeka.

Tokom pređašnjeg perioda fasada je više puta bila renovirana, ali sa manjom uspešnošću, te se uočavaju različiti koloriti u opeci i kamenu, što narušava sklad i harmoniju.prozračnog.

\section{FUNKCIONALNA ŠEMA KOMPLEKSA}

\subsection{Namena objekta}

Objekat 1, slika 4. predviđen za hotelski smeštaj gostiju, sa sobama različitih dimenzija i mogućnosti smeštajajednokrevetne i višekrevetne sobe, sa osnovnim mobilijarom.

Kubus 2 je namenjen za teretanu javnog karaktera, dok su unutrašnje zone 4 i 5 i kubus 3 rezervisani za umetnički izražaj korisnika- projektovani su ateljei za vajare, slikare, prostorije za ostavu i izložbeni prostori.

$\mathrm{U}$ istočnoj zoni se nalaze manji moduli za prodajne objekte proizvoda nastalih kroz kreativni izraz članova Bahnbetriebswerk objekta ( zona 6).

Najistočniji kubus 7 je rezervisan za složenu proizvodnju komposta i organske porizvodnje voća, povrća i začinskog bilja. Poseban karakter prostor daju otvorene površine sa planskim mobilijarom, koji nudi mesta za socijalizaciju mladih, dece i korisnika starije dobi, koji se međusobno prožimaju, ali takođe daju i mogućnost za osamljivanje i uživanje u lepotama pjezaža i netaknute okoline objekta. Hotelski smeštaj kao i umetnički ateljei su predviđeni kao jednospratne jedinice, u koje su implementirane obnovljena stepenišna jezgra i dodate rampe i liftovska jezgra kao deo osavremenjivanja prostora.

Obezbeđene su i sve dodatne prostorije za neometani rad zaposlenih, kao i predivan pogled na atrijumsko dvorište u centralnoj zoni i pogled na aktuelna dešavanja u zoni 7 kompleksa, slika 5. i slika 6.

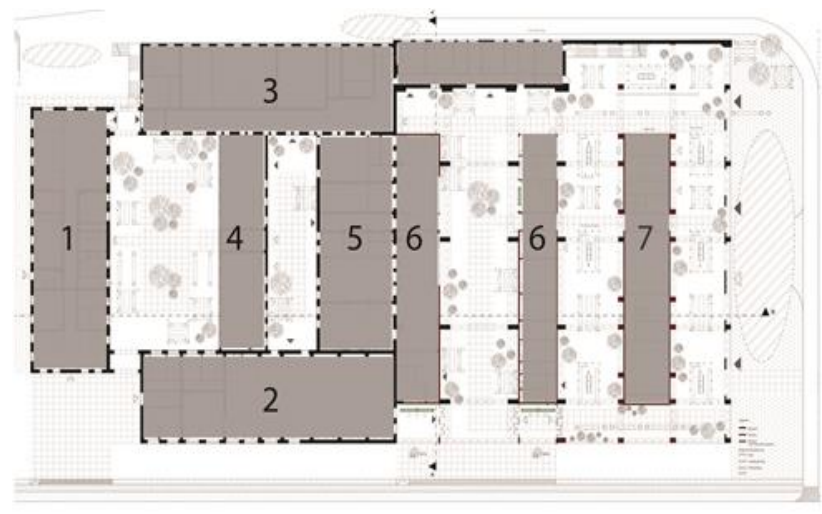

Slika 4. Šematski prikaz namene objekta

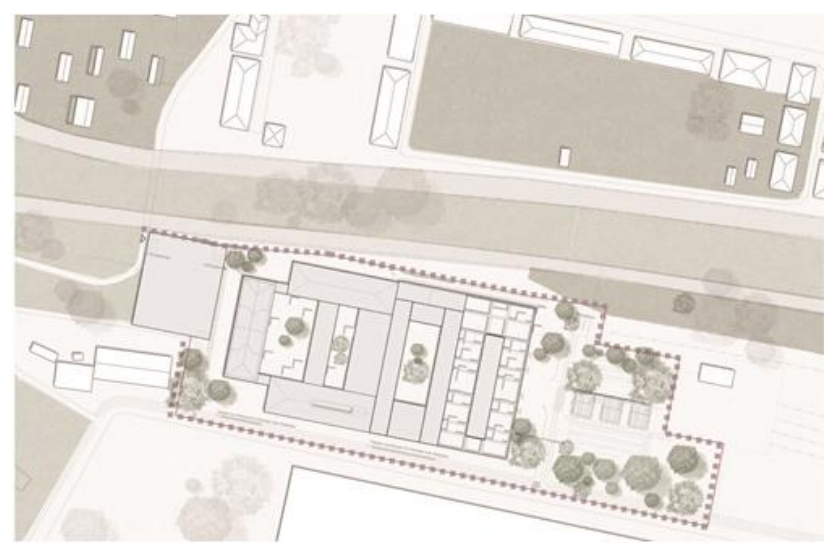

Slika 5. Šira situacija sa petom fasadom

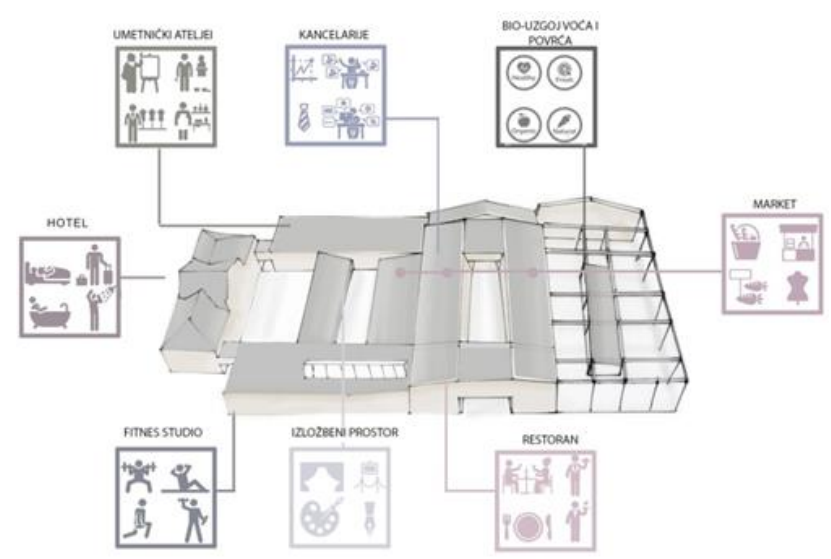

Slika 6. Prikaz primarnih namena kompleksa

\section{ZAKLJUČAK}

Projekat Restauracije depoa stare Železničke stanice predstavlja detaljan rad na veoma kompleksnom i na više nivoa izazovnom objektu, koji ima mnogostruki značaj za grad Hajdelberg.

Prvenstveno, značaj ostvaren kroz nekadašnji značaj depoa železničke stanice u veoma složenom sistemu železničkih pruga i infrastrukture u državi koja je jedna od najvećih ekonomskih sila Evrope.

Bez ovakvih tipova objekata, sama privreda i razvoj Nemačke ne bi bio moguć, te je sa istorijskog aspekat, objekat Bahnbetriebswerk od izuzetnog značaja. Takođe, u modernom, urbanom kontekstu objekat je značajan kao jedna od repernih tački za novonastali, ambiciozni projekat najvećeg eko-naselja u Evropi, Bahnstadt-a.

Ovaj projekat iako još uvek u izgradnji, predstavlja veliki pomak u tehnološkom i tehničkom razvoju države Nemačke u njenom stremljenju ka lidertsvu na polju ekološke gradnje i strogih zakona u arhitekturi, građevini i urbanističkom projektovanju.

Bahnstadt je naselje, za čiju izgradnju je bila potrebna sistematična strategija i ozbiljna finansijska ulaganja, koja su delimično izdvojena i za ovaj objekat.Zahvaljujući epitetu eko-naselja, svi objekti unutar ovog kompleksa moraju da podležu ozbiljnim ekološkim zakonima i da se uklapaju i dugoročni održivi plan razvoja nemačke države.

Samim tim i objekat depoa stare Železničke stanice je tokom ovog šestomesečnog projekta prošao mnogobrojne faze planiranja u duhu modernog sagledavanja arhitekture 
kroz prizmu održivosti i energetske efikasnsoti, te je finalni proivod objekat visokih ekoloških karakteristika.

\section{LITERATURA}

[1] Allianz für Wohnen, (2019). Nachhaltige Innenentwicklung für Wohnungsbau. Septembar 2019.

Hessen: Hessisches Ministerium für Umwelt, Klimaschutz, Landwirtschaft und Verbraucherschutz, 76. Strana 56, D.9 Bahnstadt| Heidelberg

[2] Uni Heidelberg, (2019), "Non-University Research Institutions - Heidelberg University", [online]

Dostupno na:https://www.uniheidelberg.de/institutions/non_univ ersity.html [preuzeto 7 Maj, 2020]

[3] Uni Heidelberg, (2020) „Studierende \& Wissenschaftlicher Nachwuchs - Universität Heidelberg“, Dostupno na:

https://www.uni-heidelberg.de/de/universitaet/datenfakten/studierende-wissenschaftlicher-nachwuchs [preuzeto 5 Maj, 2020]
[4] Vierra S, (2018). Green building standards and certifications. September 2017. Dostupno na: https://www.wbdg.org/resources/green-buildingstandards-and-certification-systems [preuzeto 10 April 2020]

\section{Kratka biografija:}

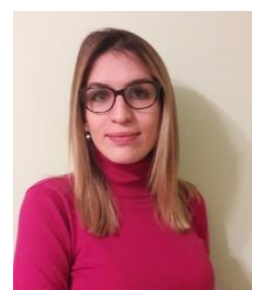

Aleksandra Panić rođena je u Novom Sadu 1995. god. Osnovne akademske studije završila je 2018. godine na Fakultetu tehničkih nauka u Novom Sadu, na kom brani i master rad 2020. godine iz studijskog programa Arhitektura-oblast Savremene teorije i tehnologije u arhitekturi. 